\title{
Microstructural Development of a Friction Stir Welded Ti-6Al-4V Sheet
}

\author{
M.W.B. Santos ${ }^{1}$, A. Farias ${ }^{2}$, M. Stipkovic Filho ${ }^{3}$, G.F. Batalha ${ }^{1, *}$ \\ ${ }^{1}$ Department of Mechatronics and Mechanical Systems Engineering, Polytechnic School of Engineering, University of Sao Paulo, Brazil \\ ${ }^{2}$ Centro Universitario da FEI, Brazil \\ ${ }^{3}$ Mackenzie Presbyterian University, Brazil
}

Copyright (C) 2015 by authors, all rights reserved. Authors agree that this article remains permanently open access under the terms of the Creative Commons Attribution License 4.0 International License

\begin{abstract}
The effect of the friction stir welding processing (FSP) speed rotation and feed rate on the microstructure of a $\mathrm{Ti}-6 \mathrm{Al}-4 \mathrm{~V}$ alloy was investigated in a 2-mm-thick alloy. The joints were processed above the $\beta$-transus temperature. The prior $\beta$-grain size in the stir zone depended on the speed rotation that is related with the peak temperature and the size of the lamellar structure depended on the feed that control the cooling rate. Some regions with bimodal refined grains structure were observed on stir zone. A hardness increase on friction stir processed region was observed in all conditions, except for 1550 RPM and feed 50 $\mathrm{mm} / \mathrm{min}$. It was associated to a coarse lamellar structure.
\end{abstract}

Keywords Microstructure, Joining, Friction Stir Welding, Titanium Alloy, Ti-6Al-4V

\section{Introduction}

Titanium and its alloys are used in aerospace, marine, chemical, petrochemical, engineering and biomedical applications because of its amazing range of properties. Some properties such as the unique relationship of high strength and low weight, good formability and fatigue resistance leads the use of titanium in various special applications where high demands (physical, chemical and / or mechanical) restrict the use of conventional materials. The high strength of titanium alloys combined with its metallurgical stability at high temperatures and its low flow rates, makes them favorable for jet engine components such as blades and disks, aerospace applications such as components for rocket engines and fuel tank. They are used in aircraft fuselage structures because of its good relationship strength/weight ratio, such as landing gear, beams, hydraulic lines, wing boxes, spacers and screws. They are also important in marine applications, where corrosion resistance is required because of sea water and acidic hydrocarbon atmospheres. In the biomedical field applications, titanium also displays a great advantage in medical use, is fully biocompatible, titanium is one of few materials that are inert to corrosion by any human body fluids and tissues, a major requirement for implantation in human body. It is used in prosthetic devices for bone and joint implants, heart valves and dental implants. These are made from commercial pure titanium, Ti-6Al-4V alloy or recently developed alloys. Nowadays over one hundred titanium alloys are known; which however, only twenty to thirty are commercially produced. In effect, the Ti-6Al-4V alloy covers more than $50 \%$ of use. Another $20 \%$ to $30 \%$ use is for pure titanium [1].

The control over microstructure, i.e. the ability to refine grains to micron or sub-micron sizes is essential to achieving the desired combination of strength and toughness in metallic materials for advanced applications. In titanium alloys it is difficult to attain such ultra-fine grain structures because of the very rapid rate of grain growth experienced in these alloys. The Ti6Al4V alloy present a bimodal structure consisted with $\alpha$ phase and $\beta$ phase, thus the control and the optimization of the microstructure of this $\alpha / \beta$ alloy is important issues to achieve desired properties [2]. The lamellar microstructure characteristic features is determined by the cooling rate, they are (i) the size of $\alpha$ lamellae ( $\alpha$ plates), (ii) the $\alpha$ colony size and (iii) the thickness of $\alpha$ layers at prior $\beta$ grain boundaries. In general it can be stated that both microstructural parameters, the width of individual $\alpha$ plates and the size of $\alpha$ colonies, decrease with increasing cooling rate [2]. The technology of friction stir welding and processing is applied for obtained a fine grain, this fact have attracted considerable attention in multiple industries because of its advantages for joining/processing of various light alloys [3]. The phase transformations and their respective predicted microstructures (Figure 1) are influenced by the friction stir processing (Figure 2 and 3) [4]. In $\mathrm{Ti}-6 \mathrm{Al}-4 \mathrm{~V}$ alloy proceed by $\mathrm{FSW}$, different microstructures can be created in the different regions (stir zone, thermo-mechanical affected zone, heat affected zone) depending on mainly the peak temperature relative to the $\beta$-transus temperature and cooling rate [4-8]. In this sense, 
the final microstructure of the friction stir welded titanium alloys, cannot be easily predicted only by equilibrium phase diagrams or even with CCT diagrams [1, 8-12].

In this sense the purposes of this study were to discuss the microstructure formation on different regions on friction stir processing in a $2 \mathrm{~mm}$ thick Ti-6Al-4V sheet, and to examine the its effects on the hardness and residual stress of the FSW joints.

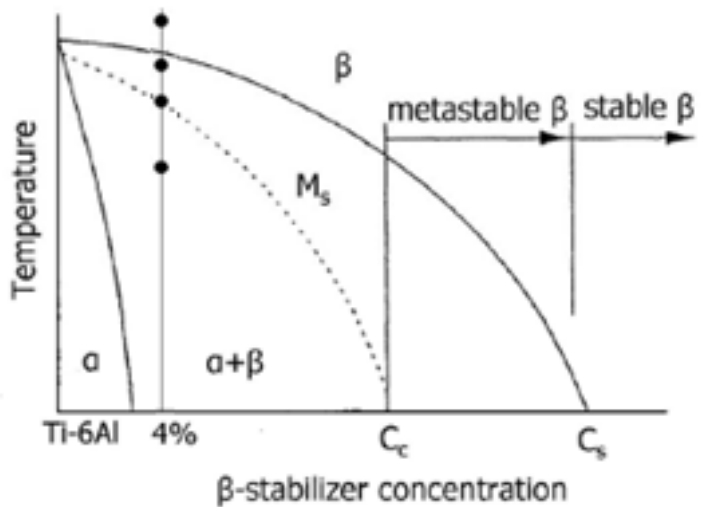

Figure 1. Pseudo-binary $\beta$-isomorphous phase diagrams: $\beta$-stabilizer for $\alpha+\beta$ alloy Ti-6Al-V4 [1].

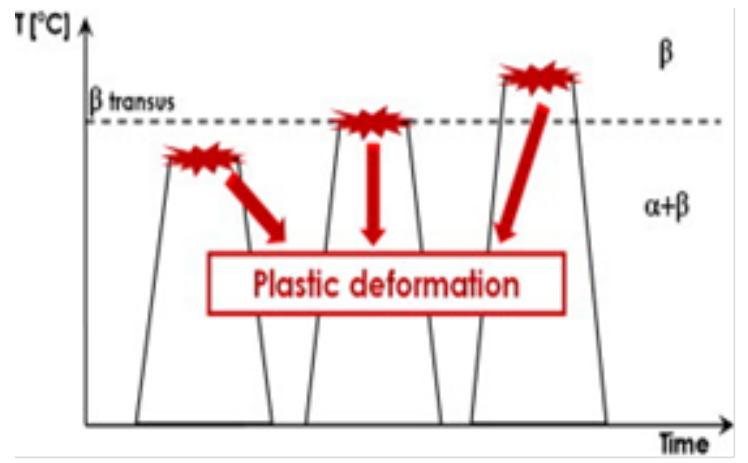

Figure 2. Combined effects on the $\beta$-transus temperature during the FSW of Ti alloys. After [11].

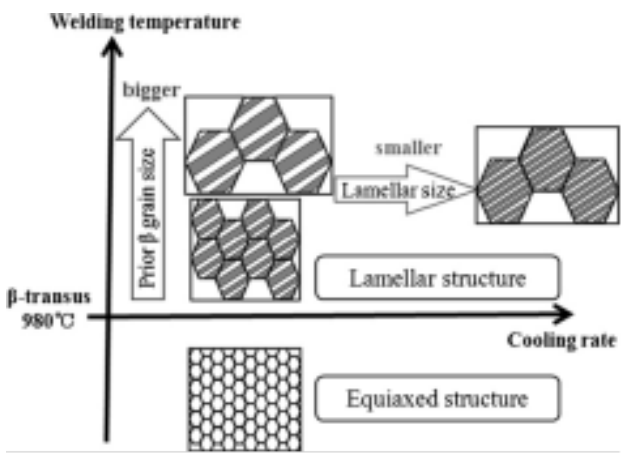

Figure 3. Illustration of FSW conditions effects on the Ti-6Al-4V microstructure. [4]

\subsection{Phases transformations of $\mathrm{Ti}-6 \mathrm{Al}-4 \mathrm{~V}$}

An overview about titanium alloy $\mathrm{Ti}-6 \mathrm{Al}-4 \mathrm{~V}$ is necessary because is very important to successfully complete the task of understanding the effect of FSW process parameters on the material microstructure and properties in different stir zones of a Ti-6Al-4V weld, it is critical that a reasonably good understanding of the physical metallurgy of this alloy be acquired. Specifically, one should become known with the stable and meta-stable phases present in this alloy system, see Figure 1. The thermal and mechanical conditions under which these phases are formed, and the effect of the material's thermal-mechanical history on its micro structure, see Figure 2, as well as the basic correlations between the phases present, their morphologies, and the resulting material properties [12].

Pure titanium undergoes, during heating, an allotropic phase transformation from a low temperature, hexagonal-close-packed $\alpha$-phase to the high-temperature, body-centered-cubic $\beta$-phase at a ('beta transus') temperature of $882.5^{\circ} \mathrm{C}$. Alloying elements can thermodynamically stabilize either $\alpha$ - or $\beta$ - phase, i.e. increase or decrease the beta-transus temperature (range). Consequently, titanium alloys may contain at room temperature different relative amounts of the two phases and are typically classified as $\alpha$-type, $\alpha+\beta$-type, and $\beta$-type alloys. Among titanium alloys, $\alpha+\beta$-type are of particular interest since vastly different mechanical properties can be imparted with various thermomechanical treatments.

Ti-6Al-4V alloy analyzed in the present work falls into the category of bi-phase $\alpha+\beta$-type titanium alloys see Figure 3 . This alloy is generally considered as the workhorse of the titanium industry and accounts for more than 50 per cent of the total titanium consumption. The alloy offers a good overall combination of the properties such as low density, high strength/stiffness, reasonably good corrosion resistance, good hot-warm and cold formability, and superior weldability with respect to fusion-based welding techniques. The maximum service temperature for Ti-6 $\mathrm{Al}-4 \mathrm{~V}$ alloy is generally quoted as $350^{\circ} \mathrm{C}$ [1].

Friction stir welding (FSW) is a relatively recent process; it was developed in the 90's for aluminum joining and now is being applied increasingly in many industries from basic materials such as steels alloys to high performance alloys such as titanium. It is a process in great development and has its economic advantages when compared to conventional welding. For high performance alloys such as titanium, a major problem to overcome is the construction of tools that can withstand the extreme process environment, in the approaching literature the possibilities are only few tungsten alloys.

An inherent characteristic of this process is the grain refinement processed in the joining region, which leads to the interest of using this as a process for grain refinement in materials where Superplasticity is a subject of study. When using as a process the best term to its definition becomes Friction Stir Processing (FSP). Rather than joining the two sheets process is used in a single plate in order to improve the characteristics of the material Superplasticity.

Figure 4 shows the typical steps of the process: (1) 
downward motion to penetrate the material; (2) linear movement on the part toward the processing direction; 3 ) end of processing and tool retraction. The tool rotation axis defines with the components to be welded an angle of inclination. This angle is used for receiving the material to be processed at the tool base and promote the gradual forge effect imposed by the shoulder during the passage of the tool. Such conception prevents the material plastic flow, ensuring weld closure on the back of the pin.

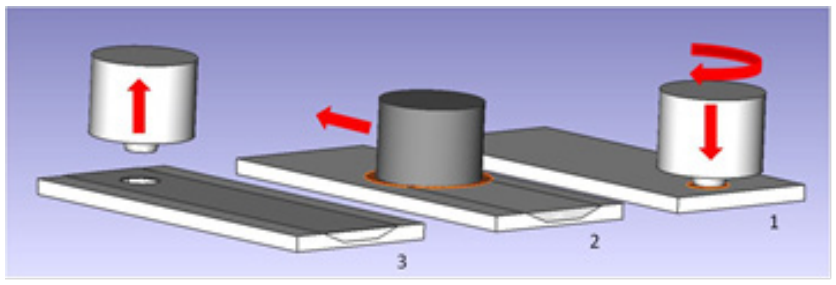

Figure 4. Typical FSW process steps

Materials with high melting point such as titanium, iron and nickel based alloy require specials wear resistant tool materials. In this sense, tungsten based alloys have been used in FSW of nickel-aluminum alloys and titanium alloys. According to [13-14] four materials with tungsten alloys were cited specifically for tools building: $\mathrm{WC}, \mathrm{W}+25 \% \mathrm{Re}$, Densimet [15] and $\mathrm{W}+1 \% \mathrm{LaO}_{2}$. Tools from tungsten-rhenium has a high operating temperature, but its construction is difficult because the need of grinding machining (more difficult than the conventional machining), and an important issue is that rhenium and tungsten materials have a high cost for production. Densimet consists of small tungsten spheres of carbide bound in a matrix containing one or other material such as nickel-iron or nickel-copper. The alloy does not have high operating temperature (compared with other tungsten alloys), however, unlike other tungsten alloys (for example tungsten-rhenium), Densimet is easily machined by conventional process and it has a lower cost. Another tungsten-based alloy is $\mathrm{W}+1 \% \mathrm{LaO}_{2}$, which has cost and workability of Densimet and the temperature range of tungsten-rhenium alloy. According to [16] a conical tool is needed because of the low thermal conductivity of titanium. A cylindrical pin tool is not indicated for titanium because heat generated in the shoulder is not able to flow to the root of the joint and allow the mixing of material in the lower plate.

\section{Materials and Methods}

\subsection{Preliminary Screening Tests}

\subsubsection{FSW parameters and variable conditions:}

Table 1 shows the resulting matrix for the preliminary planning, the array is in random sequence between the test and standard sequence and $a_{p}$ is the depth of penetration. Although it was performed a factorial design, analysis of all results versus the FSW experimental conditions could not be raised for reasons of measuring equipment availability.

Table 1. Design of the FSW Experiments - preliminary planning.

\begin{tabular}{|c|c|c|c|}
\hline Test Sequence & Rotation [RPM] & feed $[\mathrm{mm} / \mathrm{min}]$ & $\begin{array}{c}\mathrm{a}_{\mathrm{p}} \\
{[\mathrm{mm}]}\end{array}$ \\
\hline 1 & 1100 & 40 & 1,65 \\
\hline 2 & 1000 & 50 & 1,65 \\
\hline 3 & 1200 & 50 & 1,60 \\
\hline 4 & 1200 & 60 & 1,65 \\
\hline 5 & 1300 & 60 & 1,65 \\
\hline 6 & 1000 & 40 & 1,60 \\
\hline 7 & 1600 & 50 & 1,65 \\
\hline 8 & 1550 & 50 & 1,65 \\
\hline
\end{tabular}

2.1.2. FSW Experimental fixed conditions

\begin{tabular}{|c|c|}
\hline Tool tilt angle: $0,5^{\circ}$ & $\begin{array}{c}\text { CNC Machine: Machining Center - } \\
\text { MAZAK model FJV 35-60 }\end{array}$ \\
\hline
\end{tabular}

\subsubsection{FSW workpiece geometry}

Titanium alloy material Ti-6Al-4V with $2 \mathrm{~mm}$ thick sheet. Figure 5 shows samples geometry.

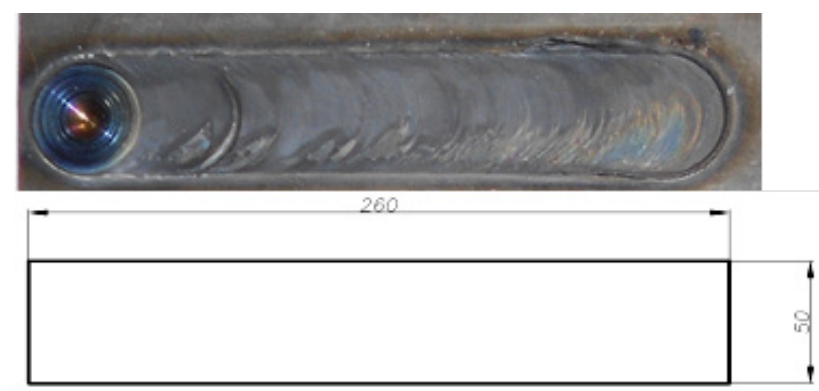

Figure 5. Macrograph of the stir zone surface and its dimensions in millimeters.

\subsubsection{FSW tool Material}

Aiming at the goal of developing a tool material that supports the FSW processing of titanium sheets, two tools were prepared with dimensions of $20 \mathrm{~mm}$ diameter shoulder, $5 \mathrm{~mm}$ diameter tapered pin with a $30^{\circ}$ angle in the cemented carbide (WC-Co) material. This alloy is successfully used in the fine blanking of holes in metal sheet at the automotive industry for the housing and screw clamps vehicle assembly. It was chosen as the first choice because the processing temperatures involved are in the order of $900^{\circ} \mathrm{C}$ to $1000^{\circ} \mathrm{C}$. Preliminary tests were performed with this tool to define the initial parameters window and specific tests for wear resistance.

\subsection{FSW Experimental Tests}

The values in Table 1 were chosen in order to prevent extreme conditions, preliminary conditions that would induce unwanted interactions between the parameters. Basically the intention is to know and understand the process for obtaining a crystal structure of grain to be used in 
superplastic tensile testing. Another important factor is to perform an evaluation of the tool design and the WC used alloy, the testing tool should be able to make the joining without wearing and without breaking. The test was carried out without any cooling at the tool in order not to decrease the process temperature. To minimize vibrations and to provide an initial guide for the tool pin a previous pilot hole was made with a twist drill in a depth of $1.60 \mathrm{~mm}$. The drill diameter $(4.8 \mathrm{~mm})$ was selected so as to be smaller than the tool tip $(5.0 \mathrm{~mm})$, therefore the tip of the tool, while executing the penetration, will generate friction with the lateral of the hole supplying heat to the initial process.

Titanium FSW process input the tool under severe strain, friction and temperature, the latter estimated at up to $900^{\circ} \mathrm{C}$ [14] which limits the use of most available materials. Despite being used in manufacture of tools where friction and temperature are high, the WC-Co tool had marked wear. Figure 6 (a) shows a new tool shoulder with a diameter of 20 $\mathrm{mm}$ and Figure 6 (b) shows the same tool after the FSW process. It is remarkable the wear on the tool tip which resulted in a poor surface finish of the sample as shown in Figure 7.

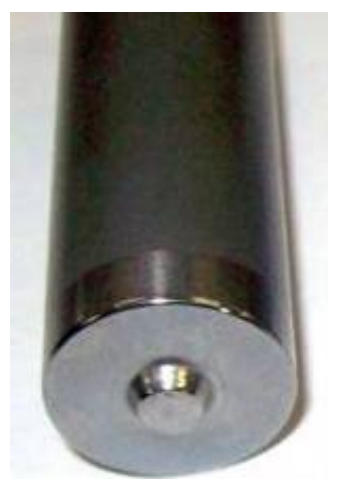

(a)

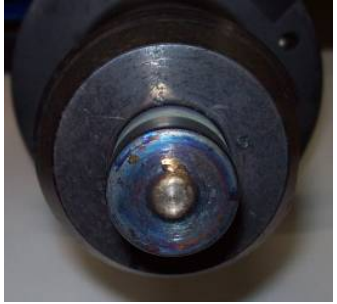

(b)
Figure 6. (a) Tool before the FSW test, (b) worn tool after the FSW test [17].

Due to process conditions, tool fragments disengaged causing scratches at the workpiece surface, within the weld detachment of tool particles was also found, these staying within the plate. In addition to the uneven surface, there was an excess of burrs resulting in further surface processing of cleaning (Figure 7).

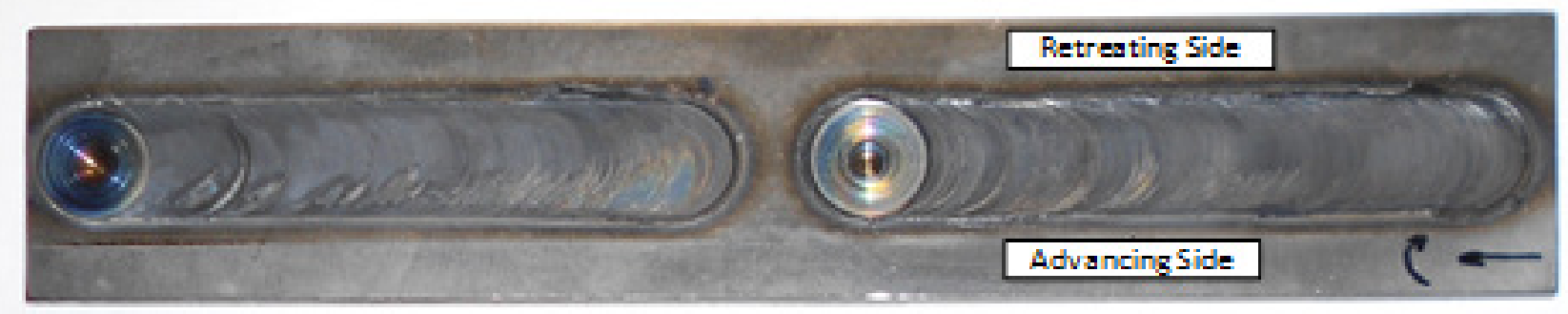

Figure 7. Ti-6Al-4V FSW workpiece $(260 \mathrm{~mm} \times 50 \mathrm{~mm})$ after FSW process, AS: advancing side of the tool, RS: retreating side of the tool. 


\section{Results}

\subsection{Hardness}

Figure 8 reports hardness as a function of position along transversal direction for all conditions. These plots clearly show a hardness increase on friction stir processed region, except condition $8,1550 \mathrm{RPM}$ and feed $50 \mathrm{~mm} / \mathrm{min}$. In this case the hardness is constant. This behavior can be attributed to a large lamellar structure resulted from a high rotation and low feed. Kitamura et al [4] showed that cooling rate decrease with feed resulting in a large lamellar structure.
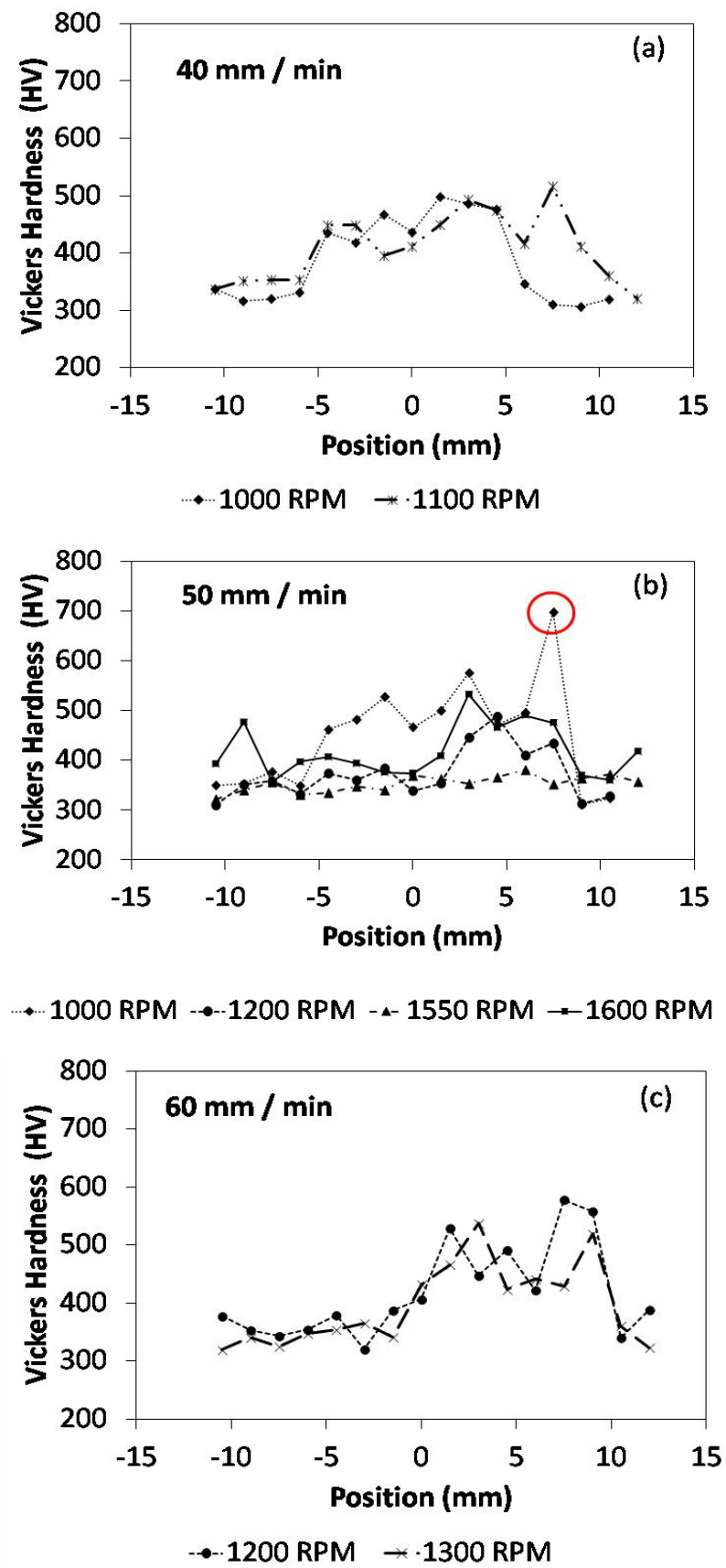

Figure 8. Vickers hardness as a function of position along transversal direction at $40 \mathrm{~mm} /$ minute (a) $50 \mathrm{~mm} / \mathrm{min}$ (b); $60 \mathrm{~mm} / \mathrm{min}$ (c).
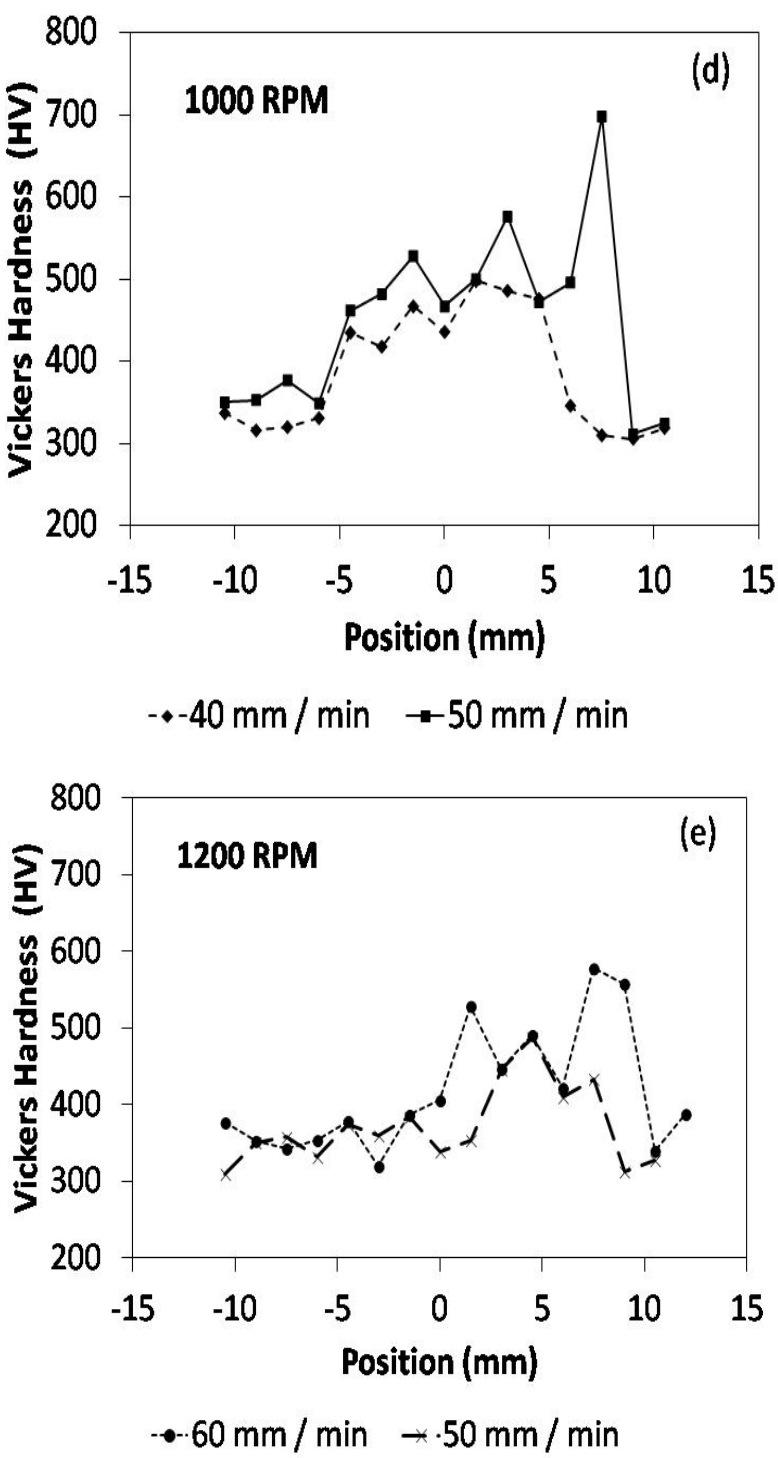

Figure 8. Continued Vickers hardness as a function of position along transversal direction at 1000 RPM (d) and 1200 RPM (e).

A previous study from the authors showed that the parameters applied with a tungsten carbide tool caused inclusions of fragments inside the samples due severe wear [18]. Figure 9 shows a SEM Backscattered electron images with EDS in some regions where tungsten fragments was observed. High hardness points on Figure $8 \mathrm{~b}$ (circles) can be attributed to tungsten fragments. In another work [17], the authors have already presented results for residual stresses that show the maximum residual stress to be located at the center of the processed region in the longitudinal direction, where the tool has performed its linear path. 

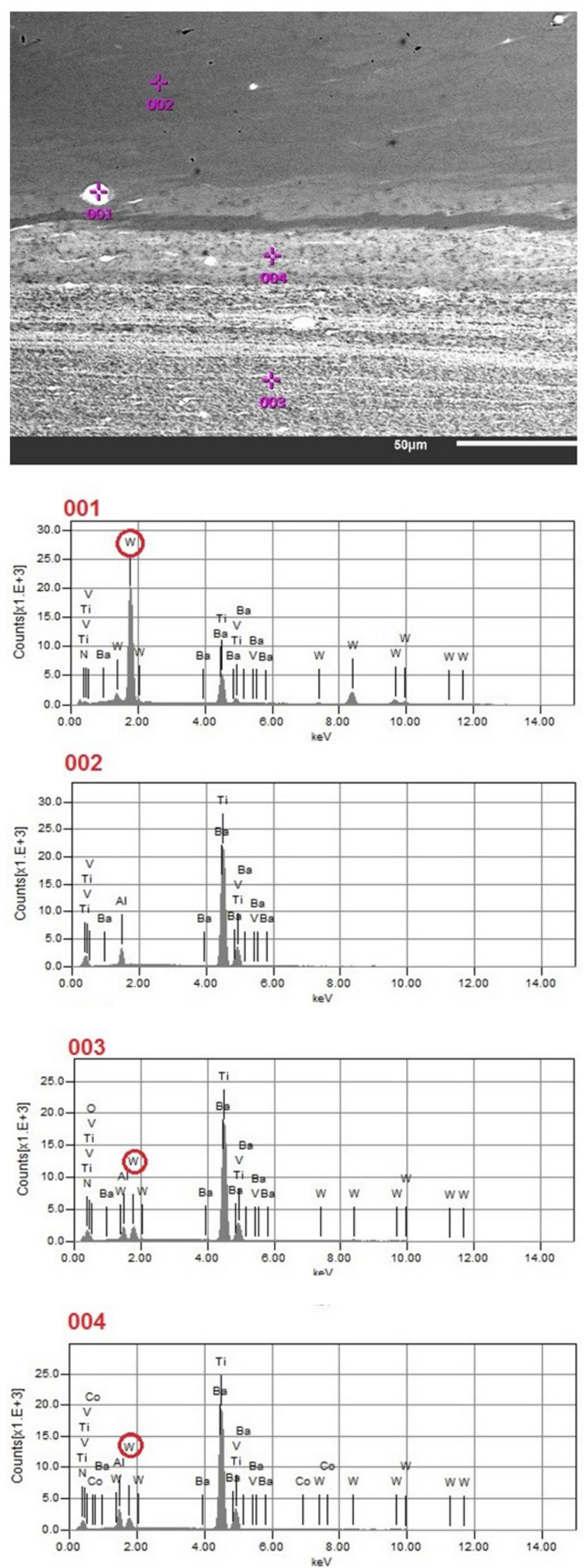

Figure 9. SEM Backscattered electron images with EDS on 1300 RPM and $60 \mathrm{~mm} / \mathrm{s}$.

\subsection{Microstructures}

SEM images of the base metal, heat affected zone (HAZ) and stir zone are shown in Figure 10 for the FSW process conditions $1600 \mathrm{rpm}-50 \mathrm{~mm} / \mathrm{min}$.

The base metal presented a bimodal microstructure consisted of $\alpha$ and $\beta$ phases as shown in the Figure 10 (a).

The heat affected zone (HAZ) microstructure was similar to that of the base metal and closer to the stir zone (SZ), the volume fraction of $\beta$ phase gradually increases because of the increase in the peak temperature, Figure $10(\mathrm{~b})$.

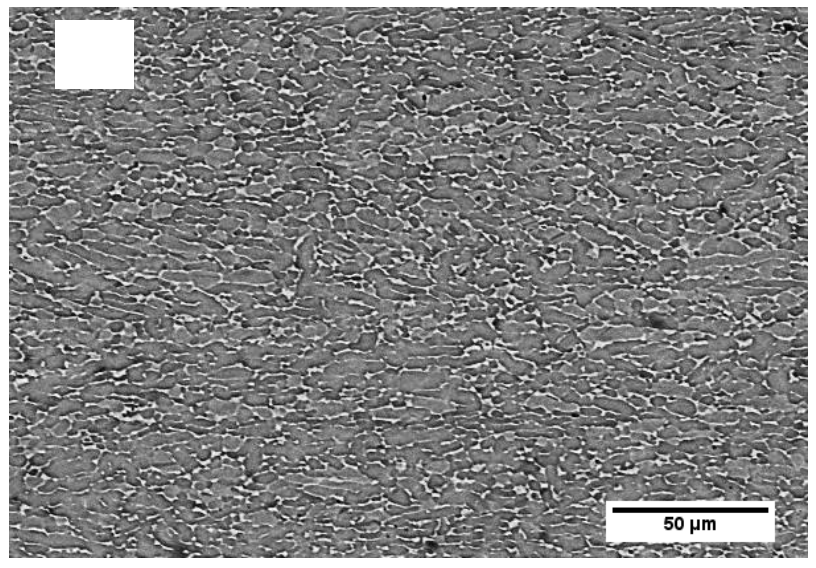

a)

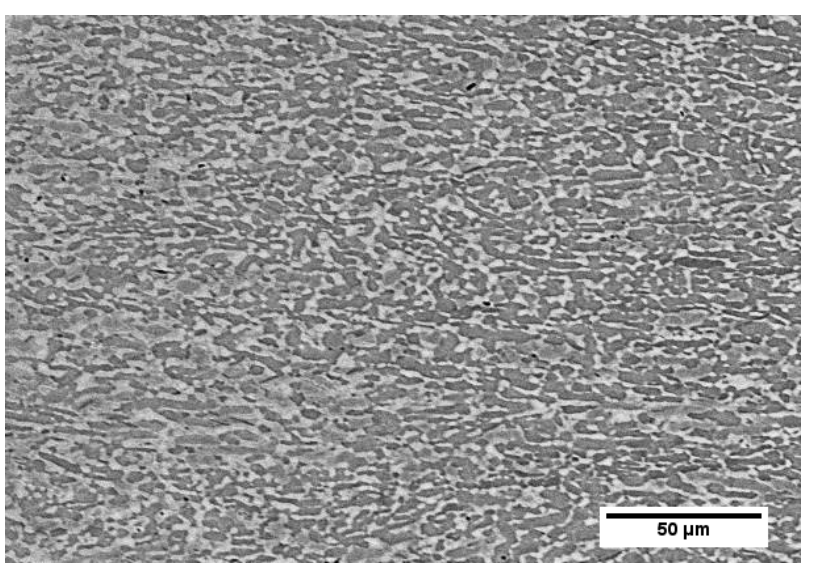

b)

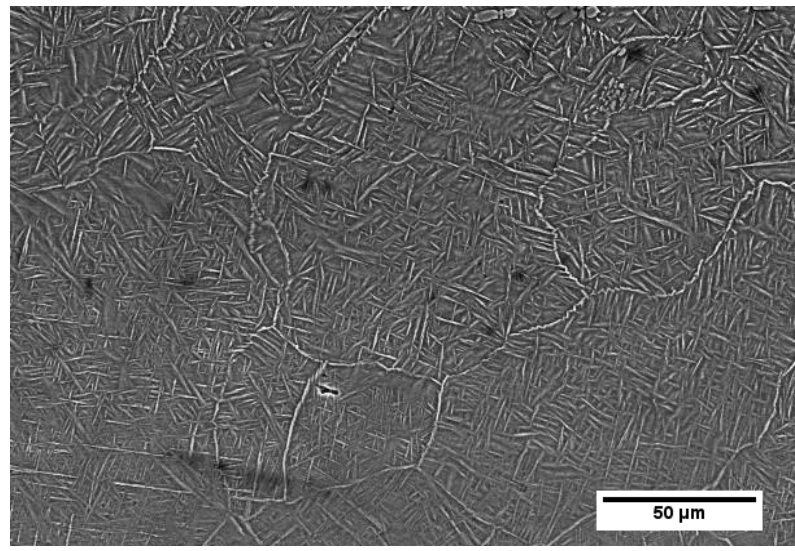

c)

Figure 10. SEM/BSE micrographs for below b-transus processing of (a) Base Metal (BM), (b) Heat Affected Zone (HAZ) and (c) Stir Zone (SZ). 
A clear thermos mechanical zone (TMAZ) was not observed in the present study; however, this zone is frequent registered in FSW joint in previous works [5-7]. It is assumed that the peak temperature in this region was sufficiently high to enable a sequence of $\alpha+\beta \rightarrow \beta \rightarrow \alpha+\beta$ phase transformation occurring due to the thermal cycle during the FSP, and the deformation characteristics in the thermos mechanical affected zone (TMAZ) may be masked by the subsequent phase transformations [5].

The microstructures in the SZ are characterized by a fully $\beta$ transformed structure, Figure10(c). This suggests that the peak temperatures in the SZ exceeded the $\beta$-transus temperature during processing, and $\beta \rightarrow \alpha+\beta$ phase transformation occurred during cooling. The transformation of the phase $\beta$ to $\alpha$ has resulted in the formation of lathes of $\alpha$ which formed on both $\beta$ grain boundaries and within the $\beta$ grain interiors (acicular $\alpha$ ).

As shown in the Figure 11, it was observed additionally small regions with equiaxed structure of grains (globular $\alpha$ ) on stir zone. Previous investigations have revealed that hot-deformation in the $\beta$-phase field accelerates the transformation of the phase $\beta$ to $\alpha$ phase, presumably due to an increase in the number of nucleation sites for the nucleation of the $\alpha$ phase. Furthermore, it was observed that the deformation increase the volume fraction of globular $\alpha$ grains, which formed along the initial $\beta$ grain boundaries [19]. In this sense, it is apparent that $\alpha$ globular region could be related to a higher deformation zone originated by friction stir processing.

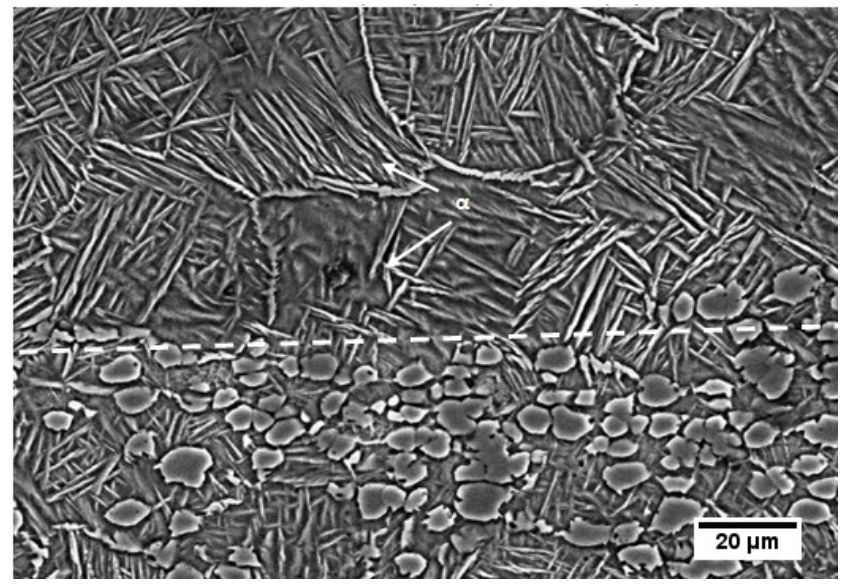

Figure 11. Micrographic of microstructure on Backscattered electron image of Stir Zone. In detail $\alpha$-laths and the dashed line corresponds to the zone between the SZ and HAZ.

\section{Conclusions}

In the present study, the micro-structural characteristics and tensile properties of Ti-6Al-4V friction stir welded joints were investigated. A bimodal microstructure was developed in the stir zone (SZ) and the size of primary $\alpha$ increases with increasing welding speed. Microstructure in the HAZ was almost not changed compared with that in the base metal
(BM) and welding speed had little influence on the HAZ microstructure. The microstructures in the SZ are characterized by a fully $\beta$ transformed structure, suggesting that the peak temperatures in the SZ exceeded the $\beta$-transus temperature during processing with higher rotational speed.

Based on the available results, it is concluded that the HAZ contains the most inferior properties and that it controls the overall structural performance of the weld. A clear TMAZ was not observed and The HAZ microstructure was similar to that of the base metal and closer to the SZ, the volume fraction of $\beta$ phase gradually increases because of the increase in the peak temperature. The weld exhibited higher hardness than the base metal and the highest hardness was found in the SZ.

The microhardness evaluation shows decreasing values at the central region of the specimens due to an increase in the rotating tool speedy. Tool rotation presented the higher influence on the microhardness final results, and as can be seen (Fig. 8-a to 8-e) higher rotations caused the lower hardness values. As it moves away from the specimen center it is possible to note the consistent reduction in the hardness values.

\section{Acknowledgements}

The authors acknowledge Uniwidia for supplying the WC-Co tools and the Polimold for supplying the FSW processing machine as well as the support of FEI and Brazil. M.W.B. Santos acknowledges CAPES for the scholarship.

\section{REFERENCES}

[1] C. Leyens and M. Peters M.: Titanium and Titanium Alloys. Fundamentals and Applications. Weinheim: WILEY-VCH Verlag, 2003. 532 p.

[2] W. Sha and S. Malinov.: Titanium alloys: modeling of microstructure, properties and applications Woodhead Publishing Limited, UK, 2009.

[3] R. S. Mishra and Z.Y. Ma.: Friction stir welding and processing, Materials Science and Engineering: R: Reports 50 (2005) 1-78.

[4] K. Kitamura, H. Fujii, Y. Iwata, Y.S. Sun and Y. Morisada, Flexible control of the microstructure and mechanical properties of friction stir welded $\mathrm{Ti}-6 \mathrm{Al}-4 \mathrm{~V}$ joints. Materials and Design, v.46 (2013) 348-354.

[5] J. Su, J. Wang, R.S. Mishra, R. Xu and J.A. Baumann. Microstructure and mechanical properties of a friction stir processed Ti-6Al-4V alloy, Materials Science \& Engineering A 573 (2013) 67-74.

[6] Y. Zhang, Y. Sato, H. Kokaw, S. Park and S. Hirano, Microstructural characteristics and mechanical properties of Ti-6Al-4V friction stir welds, Materials Science and Engineering A 485 (2008) 448-455 
[7] H. J. Liu, L. Zhou and Q.W. Liu, Microstructural characteristics and mechanical properties of friction stir welded joints of Ti-6Al-4V alloy, Materials \& Design 31 (2010) 1650-1655

[8] R. Dabrowski, R., Analysis of the critical temperatures, hardness and microstructure changes of Ti6Al4V alloy during cooling from two-phase $\alpha+\beta$ and one-phase $\beta$-range, Ores and Non-Ferrous Metals, v.10, (2010), p.708-716,

[9] R. Dabrowski, The kinetics of phase transformations during continuous cooling of the Ti6Al4V alloy from the diphase $(\alpha+\beta)$ range, Archives of Metallurgy and Materials, v. 56, n. 2 (2011) 5. pp. 217-221.

[10] R. Dabrowski, The kinetics of phase transformations during continuous cooling of the Ti6Al4V alloy from the single phase $(\beta)$ range, Archives of Metallurgy and Materials, v. 56, n. 3 (2011), pp. 703-707.

[11] Buffa G., Fratini L. \& Micari F. Mechanical and microstructural properties prediction by artificial neural networks in FSW processes of dual phase titanium alloys, Journal of Manufacturing Processes 14 (2012) 289-296.

[12] M. Grujicic , G, Arakere, B. Pandurangan, A. Hariharan, B.A. Cheeseman, C-F Yen and C. Fountzoulas Computational analysis and experimental validation of the friction-stir welding behaviour of $\mathrm{Ti}-6 \mathrm{Al}-4 \mathrm{~V}$, Proc. of the Institution of Mechanical Engineers, Part B: Journal of Engineering Manufacture 225 (2011) 208-223.
[13] D.G. Sanders, M. Ramulu, P.D. Edwards and A. Cantrell, Effects on the Surface Texture, Superplastic Forming and Fatigue Performance of Ti-6Al-4V Friction Stir Welds, J. of Materials Engineering and Performance, 19, 4, (2010) 503-9.

[14] P.M. Mashinini. Process window for Friction Stir Welding of $3 \mathrm{~mm}$ Titanium (Ti-6Al-4V), 2010, $143 \mathrm{p}$. Master dissertation: Faculty of Engineering, the Built Environment and Information Technology. Port Elizabeth, South Africa, 2010.

[15] Plansee. Brochure "Densimet-Inermet-Tungsten Alloys". [S.1.], p. 16. 2012. Found at / http://www.plansee.com/en/Materials-Tungsten-403.htm

[16] P. Edwards and M. Ramulu, Effect of process conditions on superplastic forming behaviour in $\mathrm{Ti}-6 \mathrm{Al}-4 \mathrm{~V}$ friction stir weld. Science and Technology of Welding and Joining, 14 (2009) 669-680.

[17] A. Farias, G.F. Batalha, E.F. Prados, R. Magnabosco and S. Delijaicov, Tool wear evaluations in friction stir processing of commercial titanium Ti-6Al-4V, Wear 302 (2013) 1327-33.

[18] G.F. Batalha, A. Farias, R. Magnabosco, S. Delijaicov, M. Adamiak and L.A. Dobrzański, Evaluation of an AlCrN coated FSW tool, Journal of Achievements in Materials and manufacturing Engineering 55/2 (2012) 607-615.

[19] A. Dehghan-Manshadi and R.J. Dippenaar. Strain-induced phase transformation during thermo-mechanical processing of titanium alloys. Materials Science and Engineering A: Structural Materials: Properties, Microstructure and Processing, 552 (2012). PP. 451-456. 